\title{
Effect of the supply voltage fluctuations on the efficiency of the technique of shaping the current spectrum generated by VSI traction drive
}

\author{
Marcin Steczek ${ }^{1, *}$ \\ ${ }^{1}$ Lodz University of Technology, Institute of Electrical Power Engineering, Faculty of Electrical, Electronic, Computer and Control \\ Engineering, ul. Stefanowskiego 18/22, 90-924, Łódź, Poland
}

\begin{abstract}
The issue of interfering influence of traction vehicles on railway traffic control systems is a serious problem posing a threat to railway traffic safety. This issue is gaining in importance as more and more vehicles equipped with traction inverters are put into service. Current harmonics generated by traction vehicles equipped with voltage source inverters can be controlled in such a way that they do not exceed the limits imposed by railway operators. One of the current harmonic control techniques, proposed by the authors, is the use of a combination of SHE (Selective Harmonic Elimination) and SHM (Selective Harmonic Mitigation) techniques to control the traction voltage source inverter. In this article, the author present the results of investigations on the influence of supply voltage fluctuations on the efficiency of shaping techniques of the current harmonic spectra taken from the DC network by VSI traction drive system, using the SHE and SHM modulation techniques. Regarding the fact that in $3 \mathrm{kV}$ DC electric traction systems, fluctuations of the vehicle's supplying voltage are accepted in a wide range, it is necessary to determine the influence of voltage changes on the proposed modulation techniques. The research object is a simulation model of traction drive which consisting of an asynchronous motor fed by a voltage source inverter. The simulation model was verified by the means of measurements performed at a low scale laboratory stand. Analysis of the tested techniques when supplying voltage is fluctuating, allows to evaluate their usefulness in real operating conditions. The results obtained for SHE and SHM techniques were compared with SPWM modulation.
\end{abstract}

\section{Introduction}

The modern traction vehicles are commonly equipped with power electronics devices to provide fluent and dynamic control over torque of traction motors. This type of devices are known to be the significant source of current harmonics which may occur as the distortion for railway signalling system. That is the reason why railway operators provides limits for admissive amplitudes of current harmonics generated by traction vehicles. For example for Polish Railways (PKP) this limits are formulated in [2]. Fig.1 ('Limits Icat') presents mentioned above limits only for frequency band 1300$3100 \mathrm{~Hz}$. This frequency band is known to be critical because of high level of current harmonics generated by traction drives and relatively low attenuation of vehicle's input filter. This was the motivation for the author to take this frequency band under consideration.

For purposes of this work 'Limits-Icat' were recalculated on the DC-link side of a low pass gammatype input filter as the 'Limits-If' (Fig. 1). The current $\mathrm{I}_{\text {cat }}$ can be easily recalculated to current $\mathrm{I}_{\mathrm{f}}$ (Fig.2), using formula (1) where impedances of the choke $Z_{\mathrm{Lf}}(j \omega)$ and the capacitor $\mathrm{Z}_{\mathrm{Cf}}(j \omega)$ are taken under consideration. This formula is correct only for high frequencies where impedance of input filter can be assumed linear:

$$
I_{f}(j \omega)=I_{c a t}(j \omega) \cdot\left[\frac{Z_{L f}(j \omega)}{Z_{C f}(j \omega)}+1\right]
$$

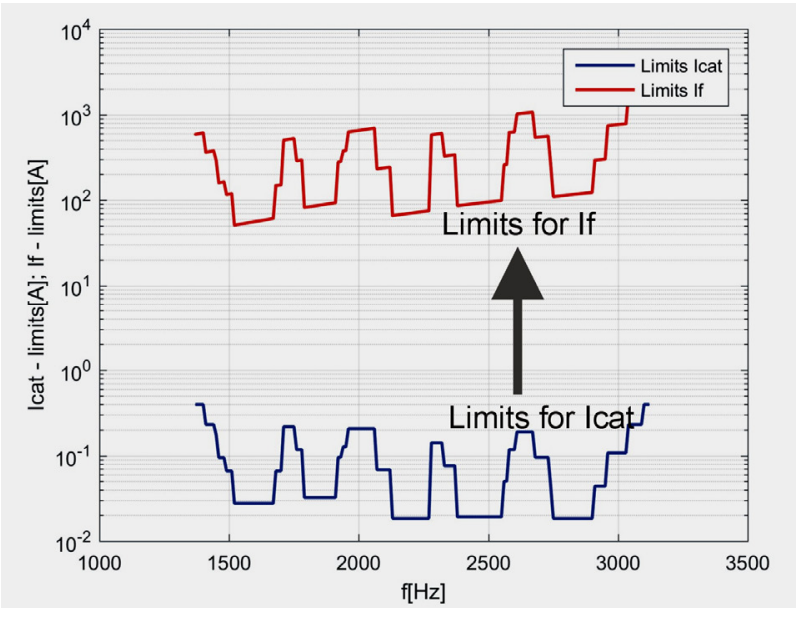

Fig. 1. Limits for catenary $\left(I_{c a t}\right)$ and recalculated for DC-link (If) current harmonics, generated by a traction vehicle in the frequency band between 1300 and $3100 \mathrm{~Hz}$;

One of the opportunities to reduce the level of distortions generated by vehicles is to apply multilevel

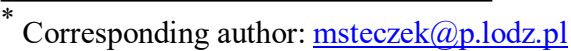


traction converters instead of two-level ones [1] [4]. However, replacement of two-level traction inverters with three-level do not solve finally the problem of distortions generated by traction vehicles. The suitable control algorithm is required.

\section{Problem description}

In previous works $[7,8,11]$ the Author presented the possibility of application of selective harmonic elimination (SHE) and selective harmonic mitigation (SHM) techniques to eliminate or control chosen current harmonics generated by traction drive to fulfil limits from Fig. 1. In mentioned analysis the DC traction power supply system was assumed to be modelled as perfect voltage source because voltage fluctuations were not in the scope of the conducted research. In this paper the Author took under consideration the influence of supply voltage fluctuation on efficiency of SHE and SHM techniques in traction current harmonics control.

The issue presented in this paper is to prove that change of supplying voltage can be compensated with change of modulation index of voltage waveform generated by traction inverter with sustained control of chosen current harmonics bellow assumed limits. The permissible changes of voltage in $3 \mathrm{kV}$ DC traction system are set between 2000 and $3600 \mathrm{~V}$ [9]. The task is to change the supplying voltage $\mathrm{U}_{\mathrm{DC}}$ in the range set by the standard and change modulation index in such a manner to keep traction drive in one operating point described by the constant value of inverter's voltage basic component $\left(\mathrm{U}_{\text {out }}\right)$. Afterwards the corrections to harmonic control strategies must be implemented to keep current harmonics below assumed limits.
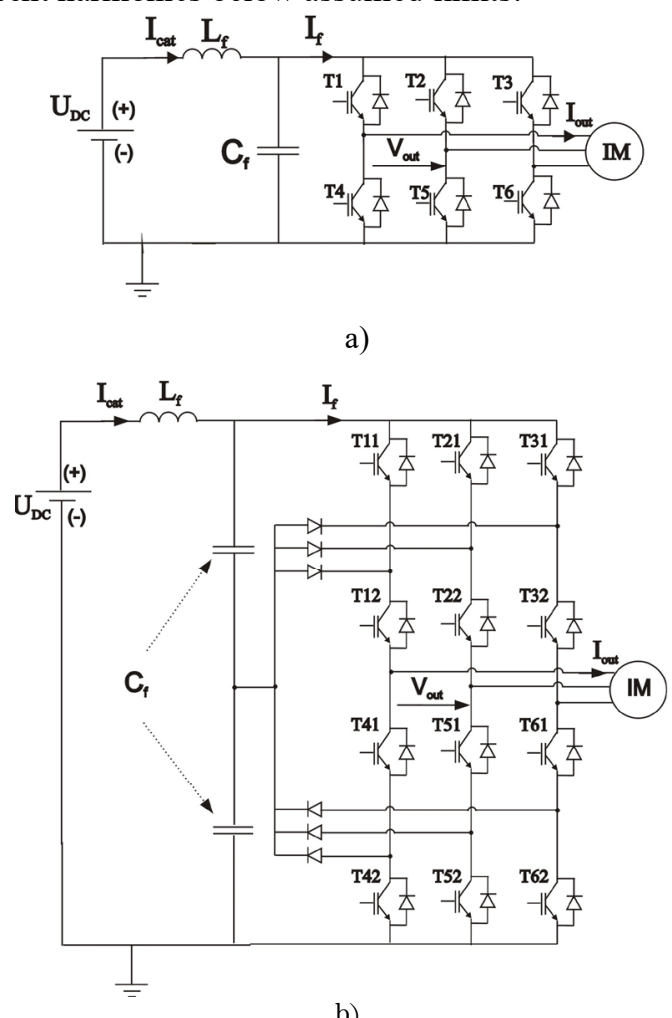

Fig. 2. Schema of the traction VSI, a) two level b) three-level.

\section{Simulation model}

The traction multi-drive simulation models were implemented using the Matlab Simulink environment. The two-level and three-level NPC VSI topology were chosen (Fig. 2). Simulation models of $500 \mathrm{~kW}$ induction traction motors were implemented. The measurement verification of simulation models used in this work was conducted on low scale laboratory model based on DSpace 1104 platform and presented in $[7,8,11]$. Simulation results were carried out for quasi-steady states of the analysed drive system with usage of time domain transient simulation option. The supply voltage was modelled as the perfect DC voltage source with variable voltage magnitude $\mathrm{U}_{\mathrm{DC}}$.

\section{Selective harmonic elimination - SHE}

The SHE modulation is one of the non-carrier based techniques. It was described for the first time in 1960s [10] and it was developed by Patel and Hoft in [5] [6]. When voltage harmonics are not eliminated but their values are set on certain values the technique is called Selective Harmonic Mitigation (SHM) [3]. SHM technique is still taken into account in the latest research and industrial applications [12, 13]. Both techniques (SHE and SHM) are based on direct determination of switching angles (time points) for VSI's transistors by solving the set of nonlinear equations, developed from the Euler's coefficients of Fourier series (2):

$$
f(\omega t)=a_{0}+\sum_{n=1}^{\infty}\left[a_{n} \sin (n \omega t)+b_{n} \cos (n \omega t)\right]
$$

where: $a_{0}, a_{n}$ and $b_{n}$ - coefficients described by the Euler's formulas.

In this paper the quarter-wave symmetry of voltage waveform is assumed. In this case for two-level inverter coefficients $a_{0}$ and $b_{n}$ are equal zero and $a_{n}$, can be described as follows:

$$
a_{n}=\left\{\begin{array}{l}
\frac{4 \cdot U_{D C}}{2 n \pi}\left[1+\sum_{i=1}^{N}(-1)^{i} \cdot 2 \cos \left(n \cdot k_{i}\right)\right] \\
\text { for odd } n \\
\text { for even } n
\end{array}\right.
$$

Therefore for three-level inverter $a_{n}$, can be described as follows:

$$
a_{n}=\left\{\begin{array}{l}
\frac{2 \cdot U_{D C}}{2 n \pi}\left[1+\sum_{i=1}^{N}(-1)^{i} \cdot \cos \left(n \cdot k_{i}\right)\right] \\
\text { for odd } n \\
\text { for even } n
\end{array}\right.
$$

where: $N$ - number of switching angles, $k$ - switching angle.

Using $N$ switching angles in quarter period $N-1$ voltage harmonics can be eliminated (or controlled) from the spectra of inverter's output voltage $\left(\mathrm{V}_{\text {out }}(\mathrm{f})\right.$ ). Regarding $[7,8,11]$ using this technique, DC side 
current harmonics spectra can be controlled indirectly to match it to the assumed limits. In next part of this paper the case of $U_{D C}$ variation for one inverter's operating point will be taken under consideration.

\section{Assumptions}

In this work one operating point of the two and threelevel traction inverter was taken under consideration with different values of supply DC voltage $\left(\mathrm{U}_{\mathrm{DC}}\right)$. The parameters of analysis starting point are presented in Table 1.

Table 1. Operating point parameters.

\begin{tabular}{|l|c|}
\hline Inverters fundamental frequency $\left(\mathbf{f}_{\text {fal }}\right)$ & $\mathbf{6 0 ~ H z}$ \\
\hline Modulation index $(\mathrm{M})$ & 0.7 \\
\hline Voltage fundamental component $\left(\mathrm{U}_{\text {out }}\right)$ & $1200 \mathrm{~V}$ \\
\hline Motor phase current $\left(\mathrm{I}_{\mathrm{ph}}\right)$ & $215 \mathrm{~A}$ \\
\hline Supplying voltage $\left(\mathrm{UDC}_{\mathrm{DC}}\right)$ & $3400 \mathrm{~V}$ \\
\hline Number of switching angles $(\mathrm{N})$ & 5 \\
\hline
\end{tabular}

The simulations were provided for one inverter with one motor but the limits for $\mathrm{I}_{\text {cat }}$ current [2] were divided by 4 ('lim/4') for case of vehicle driven by 4 motors and by $8\left(' \mathrm{lim} / \mathrm{8}^{\prime}\right)$ for case of double traction units. The limits were recalculated od DC-link current $I_{f}$ regarding equation (1). The inductance and capacity of gamma filter were assumed as follows: $\mathrm{L}_{\mathrm{f}}=8.7 \mathrm{mH}$, $\mathrm{C}_{\mathrm{f}}=6.5 \mathrm{mF}$ The aim of the study is to select a control strategy to meet the most restrictive ' $\mathrm{lim} / 8$ ' limits. for operating point from Table 1 the elimination of the lowest voltage harmonics was chosen $\left(5^{\text {th }}, 7^{\text {th }}, 11^{\text {th }}\right.$ and $13^{\text {th }}$ ) On Fig. 3 it is shown that this control strategy is effective for $3400 \mathrm{~V} \mathrm{U}_{\mathrm{DC}}$. All current harmonics ale below assumed 'lim $/ 8$ ' limits. In next part of this paper a variation of $U_{D C}$ will be implemented.

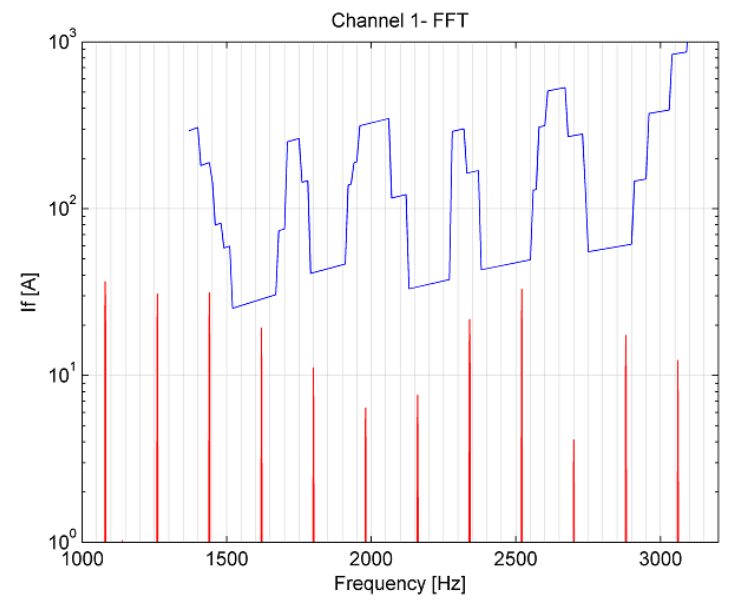

Fig. 3. If current harmonics with SHE modulation $\mathrm{M}=0.7$, $\mathrm{UDC}_{\mathrm{DC}}=3400 \mathrm{~V}$.

To prove the advantage of SHE over different modulation techniques the SPWM technique was implemented for the same operating point of the model.
Fig. 4 present $I_{f}$ current harmonics and it can be observed that for SPWM technique current harmonics exceeded assumed limits.

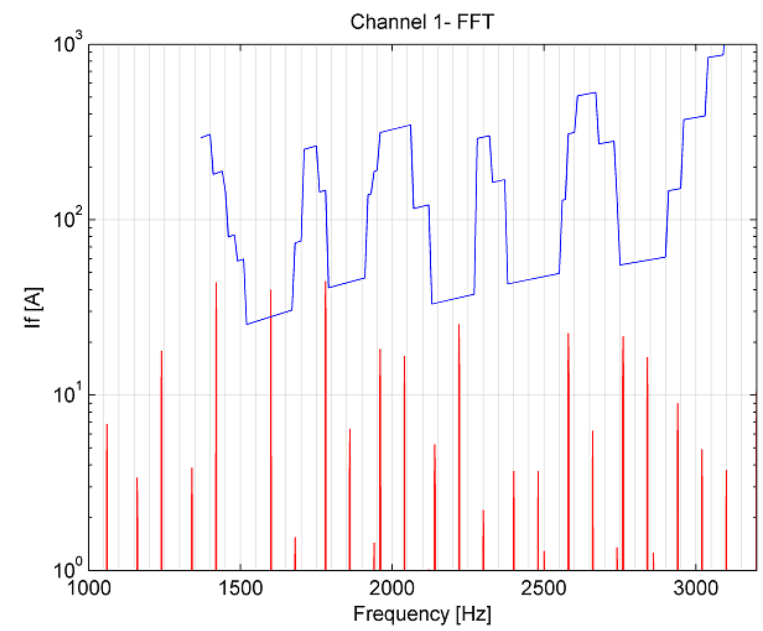

Fig. 4. If current harmonics with SPWM modulation $\mathrm{M}=0.7$, $\mathrm{UDC}_{\mathrm{DC}}=3400 \mathrm{~V}$.

\section{Simulation results for three-level inverter}

In this section the simulation results for three-level NPC inverter will be presented. In the first place the SHE strategy will be the same for all values of supplying voltage $U_{D C}$, only modulation index will be changed to keep constant value of VSI's output voltage basic component $\mathrm{U}_{\text {out }}=1200 \mathrm{~V}$ to keep traction drive in the same operating point. That means 5th, 7th, 11 th and 13th voltage harmonics will be eliminated and modulation index will change according to values from Table 2.

Table 2. Modulation index correction regarding $U_{D C}$ variations.

\begin{tabular}{|c|c|c|c|c|c|c|}
\hline & \multirow{2}{*}{$\begin{array}{c}\mathbf{U}_{\text {DC }} \\
{[\mathbf{V}]}\end{array}$} & $\mathbf{M}$ & \multicolumn{3}{|c|}{$\mathbf{V}_{\text {out }}$ voltage harmonics $[-]$} \\
\cline { 5 - 7 } & {$[-]$} & $\mathbf{5}^{\text {th }}$ & $\mathbf{7}^{\text {th }}$ & $\mathbf{1 1}^{\text {th }}$ & $\mathbf{1 3}^{\text {th }}$ \\
\hline OP1 & 3600 & 0.66 & 0 & 0 & 0 & 0 \\
\hline OP2 & 3400 & 0.70 & 0 & 0 & 0 & 0 \\
\hline OP3 & 3200 & 0.75 & 0 & 0 & 0 & 0 \\
\hline OP4 & 3000 & 0.80 & 0 & 0 & 0 & 0 \\
\hline OP5 & 2800 & 0.85 & 0 & 0 & 0 & 0 \\
\hline OP6 & 2600 & 0.92 & 0 & 0 & 0 & 0 \\
\hline OP7 & 2400 & 1.00 & 0 & 0 & 0 & 0 \\
\hline
\end{tabular}

Fig. 5 presents the values of $\mathrm{I}_{\mathrm{f}}$ current harmonics for $\mathrm{U}_{\mathrm{DC}}$ values from Table 2 . It can be observed that for points describes in Table 2 as OP4, OP5, OP6 limits 'lim/8' are exceeded by harmonic $1620 \mathrm{~Hz}$. The conclusion is: for this point, correction of control strategy is required. 


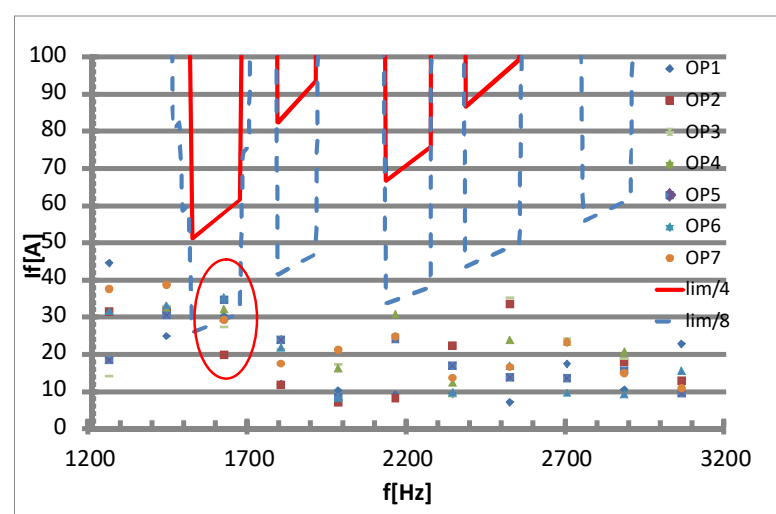

Fig. 5. If current harmonics for different values of UDC and modulation index M (Table 2)-for three-level inverter.

For cases where limits were exceeded the SHE strategy was replaced by SHM with suitable values of mitigated harmonics. The pattern of harmonics control is presented in Table 3. Fig. 6 presents $\mathrm{I}_{\mathrm{f}}$ current harmonics for $\mathrm{U}_{\mathrm{DC}}$ values from Table 3 with revised control strategy to meet limits 'lim/8'.

Table 3. Revised voltage harmonics control strategy.

\begin{tabular}{|c|c|c|c|c|c|c|}
\hline & \multirow{2}{*}{$\begin{array}{c}\mathbf{U}_{\mathbf{D C}} \\
{[\mathbf{V}]}\end{array}$} & $\mathbf{M}$ & \multicolumn{4}{|c|}{$\mathbf{V}_{\text {out }}$ voltage harmonics [-] } \\
\cline { 4 - 7 } & {$[-]$} & $\mathbf{5}^{\text {th }}$ & $\mathbf{7}^{\text {th }}$ & $\mathbf{1 1}^{\text {th }}$ & $\mathbf{1 3}^{\text {th }}$ \\
\hline OP1 & 3600 & 0.66 & 0 & 0 & 0 & 0 \\
\hline OP2 & 3400 & 0.70 & 0 & 0 & 0 & 0 \\
\hline OP3 & 3200 & 0.75 & 0 & 0 & 0 & 0 \\
\hline OP4 & 3000 & 0.80 & 0 & 0 & 0.11 & 0.13 \\
\hline OP5 & 2800 & 0.85 & 0 & 0 & 0.11 & 0.13 \\
\hline OP6 & 2600 & 0.92 & 0 & 0 & 0.11 & 0.15 \\
\hline OP7 & 2400 & 1.00 & 0 & 0 & 0 & 0 \\
\hline
\end{tabular}

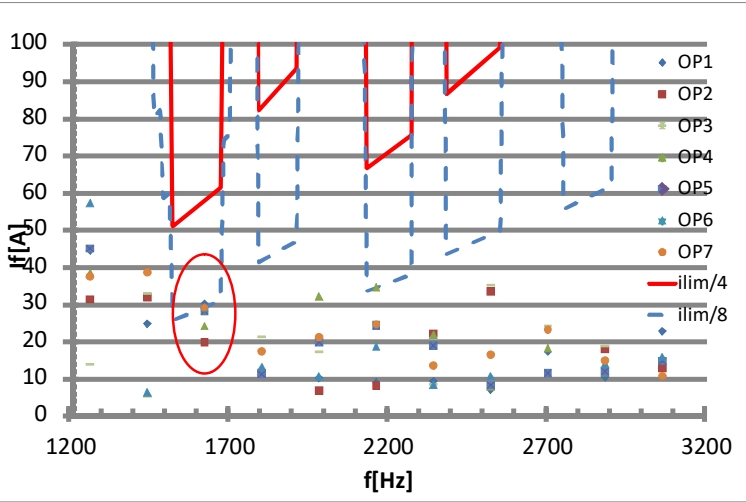

Fig. 6. If current harmonics for different values of UDC and modulation index M (table 3) )-for three-level inverter.

The following conclusion can be formulated: for chosen operating point of traction inverter the combination of SHE and SHM techniques can provide positive results in full range of supply voltage $U_{D C}$. Increasing of chosen voltage harmonics in SHM technique brings disadvantage in the form of increased THD of motor phase current and what follows increment of losses. The change of THD is presented in Fig. 7. It can be observer that maximum THD increment is $0.4 \%$ for point OP4 and OP6, and it is relatively low in comparison to the benefits of meeting the compatibility requirements.

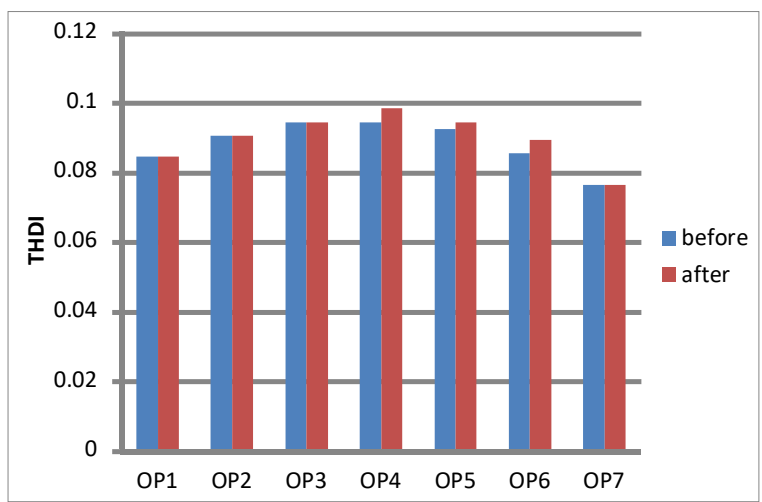

Fig. 7. THD I 'before' and 'after' revision of voltage harmonics control strategy for three-level inverter.

\section{Simulation results for two-level inverter}

In this section the results for two-level inverter will be presented. The approach to the problem will be similar to that presented in Section 6. Firstly the inverter's operating points from Table 4 will be analysed, taking into account the change of the supply voltage $U_{D C}$ without correction of the harmonic elimination strategy. The results from this stage of work are presented in Fig. 8. It can be observed that current harmonic of 2160 $\mathrm{Hz}$ frequency exceeds the assumed limits for most operating points that were taken under consideration.

Table 4. Modulation index correction regarding $U_{D C}$ variations

\begin{tabular}{|c|c|c|c|c|c|c|}
\hline & \multirow{2}{*}{$\begin{array}{c}\mathbf{U}_{\text {DC }} \\
{[\mathbf{V}]}\end{array}$} & M [-] & & \multicolumn{4}{|c|}{$\mathbf{U}_{\text {out }}$ voltage } & 7th & 11th & 13th \\
\hline OP1 & 3600 & 0.66 & 0 & 0 & 0 & 0 \\
\hline OP2 & 3400 & 0.70 & 0 & 0 & 0 & 0 \\
\hline OP3 & 3200 & 0.75 & 0 & 0 & 0 & 0 \\
\hline OP4 & 3000 & 0.80 & 0 & 0 & 0 & 0 \\
\hline OP5 & 2800 & 0.85 & 0 & 0 & 0 & 0 \\
\hline OP6 & 2600 & 0.92 & 0 & 0 & 0 & 0 \\
\hline OP7 & 2400 & 1.00 & 0 & 0 & 0 & 0 \\
\hline
\end{tabular}

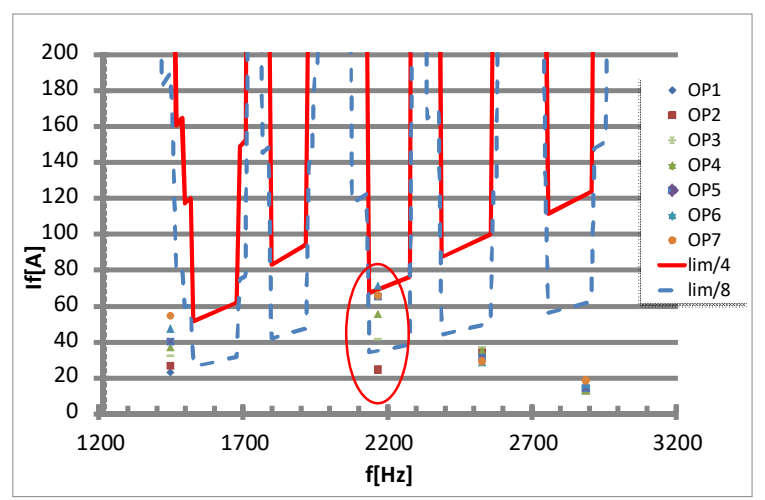

Fig. 8. If current harmonics for different values of $U_{D C}$ and modulation index M (Table 4)-for two-level inverter. 
The second step is to adjust the strategy of harmonics control to prevent exceeding the limits. The new strategy is described in Table 5. Fig. 9 presents that assumed limits are not exceeded using revised strategy.

Table 5. Revised voltage harmonics control strategy.

\begin{tabular}{|c|c|c|c|c|c|c|}
\hline & \multirow{2}{*}{$\mathbf{U}_{\text {DC }}$} & \multirow{2}{*}{$\mathbf{M}_{\mathbf{V}}[-$} & \multicolumn{4}{|c|}{$\mathbf{U}_{\text {out }}$ voltage harmonics [-] } \\
\cline { 4 - 7 } & {$[\mathbf{V}]$} & $\mathbf{5}$ & 5th & 7th & 11th & 13th \\
\hline OP1 & 3600 & 0.66 & 0 & 0 & 0 & 0 \\
\hline OP2 & 3400 & 0.70 & 0 & 0 & 0 & 0 \\
\hline OP3 & 3200 & 0.75 & 0 & 0.1 & 0 & 0 \\
\hline OP4 & 3000 & 0.80 & 0 & 0.1 & 0 & 0.15 \\
\hline OP5 & 2800 & 0.85 & 0 & 0.1 & 0 & 0.1 \\
\hline OP6 & 2600 & 0.92 & 0 & 0.1 & 0 & 0.22 \\
\hline OP7 & 2400 & 1.00 & 0 & 0.1 & 0 & 0.1 \\
\hline
\end{tabular}

The disadvantage of this method is negative impact on motor phase current THD (Fig. 10). The THD increase can reach even $2 \%$. That means the losses in motor will increase as well. However the compatibility issues have priority, thus the proposed method is effective and ready for implementation in traction drives.

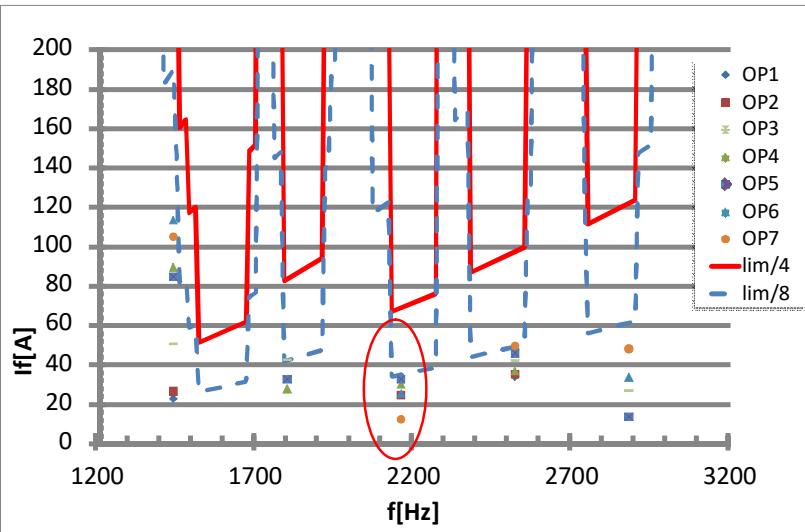

Fig. 9. If current harmonics for different values of UDC and modulation index M (table 5) )-for two-level inverter.

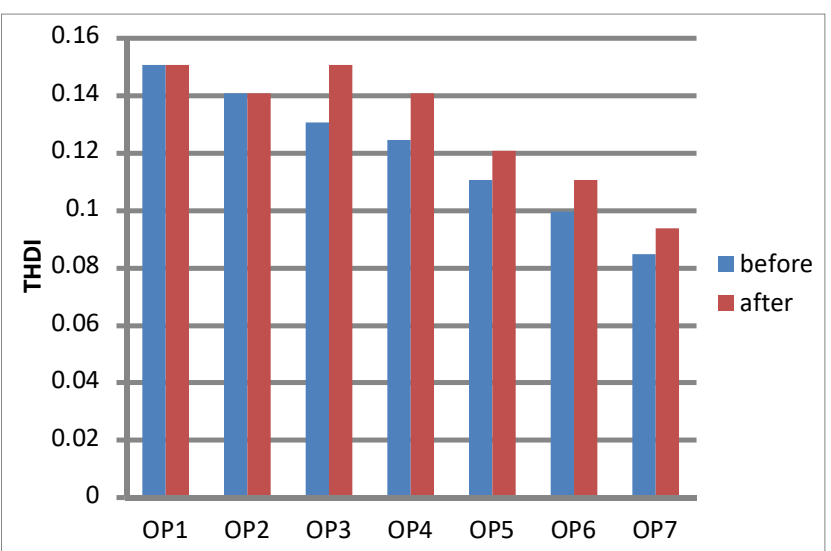

Fig. 10. THD I 'before' and 'after' revision of voltage harmonics control strategy for two-level inverter.

\section{Conclusions}

The variations of supplying voltage is a usual phenomenon in the electric traction power supply system. It is essential to take it under consideration during development of new traction drive control strategy. In this paper the Author presented the example of suggested corrections which must be implemented in SHE and SHM techniques to compensate the effect of DC voltage changes in traction drives. It was presented that using of proposed techniques it is possible to find solution which fulfil assumed restrictions regarding current harmonics in full range of DC voltage variations. The analysis were provided for both: two and three-level traction VSI. For every operating point of the VSI the different values of the supplying voltage must be taken under consideration. It is time consuming process but calculations are provided offline only once and implemented for whole lifetime of the drive. Presented work will be essential input in developing fully functional traction drive system based on SHE and SHM techniques.

\section{References}

1. H. Bernhard, A. Mariscotti, D. Wuergler. Recommendations for the calculation of the total disturbing return current from electric traction vehicles. IEEE Transactions on Power Delivery 19.3 (2004): 1190-1197 (2004)

2. A. Białoń, A. Kazimierczak, J. Furman, Ł. Zawadka, D. Adamski, P. Pajka, K. Ortel. Defining limits and levels of disturbances in signalling and control railway systems (in Polish). Railway Institute, Warsaw, Report $4430 / 10$ for PKP PLK S.A. (2011)

3. J. Napoles, J. I. Leon, R. Portillo, L. G. Franquelo, M. A. Aguir. Selective Harmonic Mitigation Technique for High-Power Converters. IEEE Trans on Ind. Electron., vol. 57, no. 7, pp.2315-2323 (2010)

4. A. Ogusola, A. Mariscotti. Electromagnetic Compatibility in Railway. Analysis and Management. Lecture Notes in Electrical Engineering., Berlin Heidelberg Springer-Verlag, pp. 1-528, ISBN 978-3-642-30281-7 (2013)

5. H. S. Patel, R. G. Hoft. Generalized techniques of harmonic elimination and voltage control in thyristor inverters: part I - harmonic elimination", IEEE Trans. Industry Applications, vol. IA-9, pp.310-317. (1973)

6. H. S. Patel, R. G. Hoft. Generalized techniques of harmonic elimination and voltage control in thyristor inverters: part II-voltage control techniques. IEEE Trans. Ind. Applications, vol. IA10, pp.666-673 (1974)

7. M. Steczek, A Szeląg. Modification of Selective Harmonics Elimination Method for Effective Catenary Current Harmonics Reduction. IEEE Int. Conf. Electrical Drives and Power Electronics (EDPE), pp. 394-401 (2015)

8. M. Steczek, P. Chudzik, A. Szeląg. Combination of SHE and SHM - PWM techniques for VSI DC-link current harmonics control in railway applications. IEEE Transactions on Industrial Electronics, 
vol.64, issue 10, DOI 10.1109/TIE.2017.2694357 (2017)

9. A. Szeląg, Z. Drążek, T. Maciołek. Elektroenergetyka miejskiej trakcji elektrycznej. Instytut Naukowo-Wydawniczy SPATIUM, Radom, ISBN 978-83-62805-42-6, page 59 (2017)

10. F. G. Turnbul. Selected harmonic reduction in static dc-ac inverters. IEEE Trans Communication and Electronics, vol. 83, pp. 374-378 (1964)

11. M. Steczek, A. Szeląg, D. Chatterjee. Analysis of disturbing effect of $3 \mathrm{kV} D C$ supplied traction vehicles equipped with two-level and three-level VSI on railway signalling track circuits. Bulletin of the Polish Academy of Sciences Technical
Sciences, Vol. 65, No. 5, 2017 DOI: 10.1515/bpasts-2017-0071 (2017)

12. M. Sharifzadeh, H. Vahedi, R. Portillo, L. G. Franquelo, K. Al-Haddad. Selective harmonic mittigation Based self-elimination of triplen harmonics for single-phase five-level inverters. IEEE Transactions on Power Electronics, earlu access DOI 10.1109/TPEL.2018.2812186 (2018)

13. A. Moeini, H. Zhao, and S. Wang, "A Current Reference based Selective Harmonic Current Mitigation PWM Technique to Improve the Performance of Cascaded H-bridge Multilevel Active Rectifiers," IEEE Transactions on Industrial Electronics, vol. 65, pp. 727 - 737, (2018) 